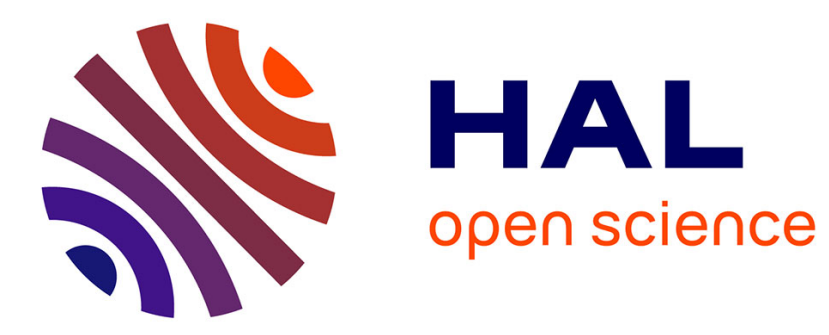

\title{
Characterization of the viscoelastic behaviour of a plastic-bonded explosive
}

\author{
Didier Picart, Jean-Luc Brigolle
}

\section{To cite this version:}

Didier Picart, Jean-Luc Brigolle. Characterization of the viscoelastic behaviour of a plasticbonded explosive. Materials Science and Engineering: A, 2010, 527 (29-30), pp.7826-7831. 10.1016/j.msea.2010.08.057 . hal-03417330

\section{HAL Id: hal-03417330 \\ https://hal.science/hal-03417330}

Submitted on 30 Nov 2021

HAL is a multi-disciplinary open access archive for the deposit and dissemination of scientific research documents, whether they are published or not. The documents may come from teaching and research institutions in France or abroad, or from public or private research centers.
L'archive ouverte pluridisciplinaire HAL, est destinée au dépôt et à la diffusion de documents scientifiques de niveau recherche, publiés ou non, émanant des établissements d'enseignement et de recherche français ou étrangers, des laboratoires publics ou privés.

\section{다)(1) $(5$}

Distributed under a Creative Commons Attribution - NonCommercial| 4.0 International 


\title{
Characterization of the viscoelastic behaviour of a plastic-bonded explosive
}

\author{
D. Picart * J.L. Brigolle \\ CEA DAM Le Ripault, BP16, F-37260 Monts, France
}

\begin{abstract}
An experimental study of the viscoelastic behaviour of a composite explosive material with an octogen content of almost $95 \%$ is presented. The addition of a plastic binder results in a material that, following isostatic compaction, exhibits a quasi-brittle behaviour that is strongly dependent on the strain rate. Some mechanical spectrometry tests were carried out in order to characterise this behaviour. The measurements were analysed using a time-temperature equivalence method. We also propose possible explanations for the irreversible phenomenon observed during the tests.
\end{abstract}

\section{Introduction}

The considered high explosive is composed of a polydisperse distribution of $0-600 \mu \mathrm{m}$ HMX grains (octahydro1,3,5,7-tetranitro-1,3,5,7-tetrazocine), with a high fraction of this distribution around $100 \mu \mathrm{m}$. These crystals are mixed with less than $5 \mathrm{wt}$ \% of a polymeric binder. An isostatic compaction process is used to reduce the porosity of the composition to approximately 2\% (see Fig. 5). The mechanical response is close to the behaviour exhibited by PBX 9501 [1-4]. The demands of pyrotechnic design and the investigation of aging behaviour both require an in-depth knowledge and modelling of the behaviour of energetic materials. Recent results [5-8] have already refined the mechanical characterization of this type of material and have led to a new constitutive law for the composite under consideration. The dynamic mechanical spectrometry technique described in this paper is a method that has the potential to be of considerable utility in this process. The second area of application relates to the safety of pyrotechnic structures, especially in relation to low velocity mechanical impacts [9]. Dynamic mechanical spectrometry, as the name suggests, may be used to subject the samples to a wide range of strain rates. This range could also be extended using a time-temperature equivalence relationship. The results obtained may be used with advantage to complement those obtained, for example, from the Split Hopkinson Pressure Bars test (SHPB). The determination of the elastic characteristics is known to be hardly tractable for brittle materials using SHPB.

\footnotetext{
* Corresponding author. Tel.: +33 2 47344173; fax: +332 47345158.

E-mail address: didier.picart@cea.fr (D. Picart).
}

In this document, we first describe the measurements made using a viscoanalyser (DMA) on a compressed HMX-based explosive material. An analysis of the plots obtained for each temperature may be used to determine the time-temperature equivalence and a master curve of the viscoelastic modules of the material (Section 2). In Section 3, we compare these measurements with those obtained on PBX 9501, a material with a similar composition and forming process. We showed that the material suffers considerable damage when subjected to thermal cycling with no other mechanical stress. The nature of this damage is discussed.

\section{Measurements using a viscoanalyser}

The METRAVIB 01DB viscoanalyser is used to apply a sinusoidal displacement to the sample under test and measures the resulting return force [10]. The measurements are analysed assuming a linear viscoelasticity, i.e. the ratio of stress to strain is a function of the frequency and temperature only. The ratio of the amplitudes of the force and displacement signals is used to determine the complex stiffness of the material, while the phase shift indicates the viscosity.

Following details of the experiments refers to test condition denoted \#1 in this paper. A traction/compression stress was applied. The samples were parallelepipeds, $50 \mathrm{~mm} \times 5 \mathrm{~mm} \times 5 \mathrm{~mm}$, and the direction of the force was parallel to the longest side of the piece (force was applied to the $5 \mathrm{~mm} \times 5 \mathrm{~mm}$ surface area). The samples were glued to a base plate using a cyanolite adhesive (Loctite $^{\circledR} 401$ ) which has an operating temperature range of -50 to $+50^{\circ} \mathrm{C}$ (glass transition temperature around $120^{\circ} \mathrm{C}$ ). A compression force of $10 \mathrm{~N}$ was applied during the gluing process in order to spread the adhesive evenly over the contact surface. This pro- 


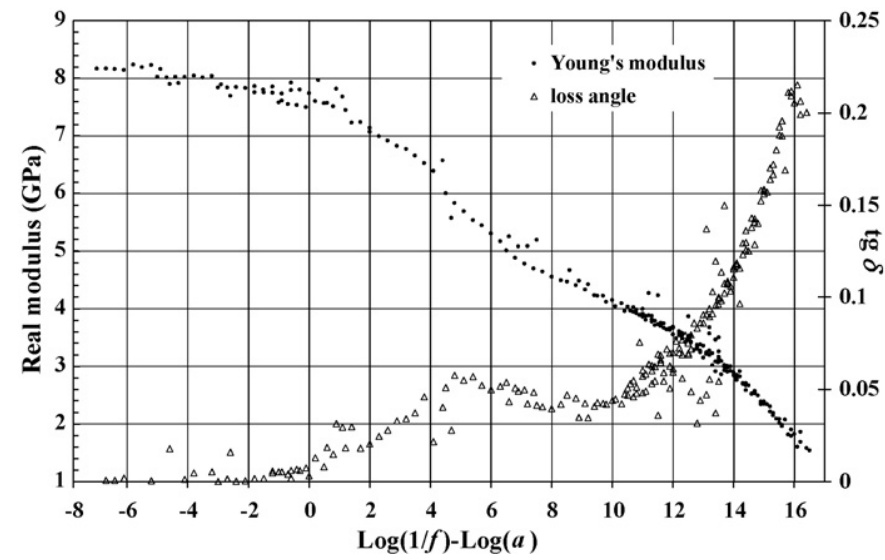

Fig. 1. Master curve of the real modulus and loss angle of the material (reference temperature: $-60^{\circ} \mathrm{C}$ ). The measurements were made between -100 and $+100^{\circ} \mathrm{C}$.

cedure also masked any surface imperfections. The adhesive sets very quickly when applied as a thin film. The strength of the bond was checked prior to the test by applying a tension force of $15 \mathrm{~N}$.

The test was carried out by applying a dynamic oscillation, parallel to the longest size of the sample, about the rest position reached at the target temperature following thermal expansion of the sample. The mechanical behaviour is assumed to be identical in tension and compression. During all the tests described below, the stiffness of the sample was verified to be less than that of the test fixture. The assumption of linear viscoelasticity was verified at a range of temperatures. However, a small reduction in the real modulus with displacement amplitude was observed at $20^{\circ} \mathrm{C}$. From previous experiences with this viscoanalyser is known that, for displacements less than $\pm 2 \mu \mathrm{m}$, the loss angle tangent cannot be measured reproducibly. A displacement of $\pm 3 \mu \mathrm{m}$ is therefore a good compromise. We have restricted the range of frequencies between 0.1 and $40 \mathrm{~Hz}$. The tests therefore correspond to strain rates of between $3.77 \times 10^{-5}$ and $1.5 \times 10^{-2} \mathrm{~s}^{-1}$. The applied engineering strain was $6 \times 10^{-5}$. Measurements were taken at a number of temperature steps. At each temperature step, a delay of 15 min was imposed in order to allow the sample to reach thermal equilibrium. Measurements were made at intervals of $10^{\circ} \mathrm{C}$ between -100 and $+100^{\circ} \mathrm{C}$ (beginning at the lower temperatures). The rate of heating and cooling was set at $5^{\circ} \mathrm{C} / \mathrm{min}$. A frequency sweep was carried out at each temperature step.

The equipment is annually calibrated, guaranteeing an accuracy of the force and displacement measurements of $\pm 2.2 \%$. The calculated stiffness is therefore accurate to within $\pm 4.8 \%$. The frequency accuracy is $\pm 0.01 \%$ and that of the phase angle is $\pm 0.1 \%$.

\section{Determination of a time-temperature equivalence}

The processing of the measurements is based on the mesh of real modulus isotherms as a function of the logarithm of inverse frequency. These isotherms are 'connected' by offsetting the curves laterally one at a time relative to the others in order to derive a single master curve. The set of offsets as a function of temperature constitutes the equivalence relationship or equivalence rule.

It can be seen (Fig. 1) that the master curve of the real modulus is relatively monotonic for values of the reduced time (logarithm of the inverse frequency minus the logarithm of the shifting factor a) greater than $1 \mathrm{~s}$ despite a number of small inflexions. A modulus of $8.2 \mathrm{GPa}$ is reached at lower values of the reduced temperature. This modulus seems to approach the vitreous modulus asymptotically. The proposed equivalence plot in Fig. 2 was compared with equivalence relationships obtained, for the same material, using traction and compression tests. These equivalence relationships

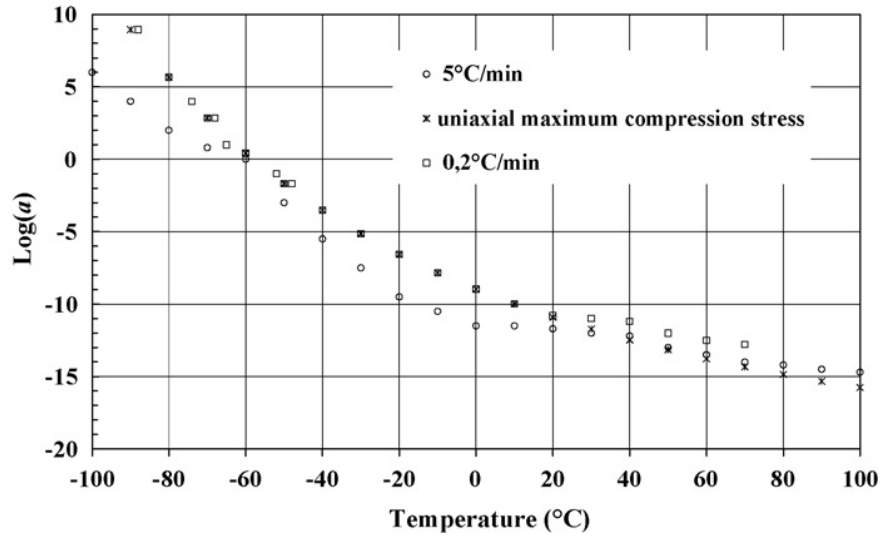

Fig. 2. Time-temperature equivalence obtained by offsetting the real modulus isotherms. Comparison with equivalences obtained (i) for a lower thermal rate (see Section 2), (ii) on the measurements of the time to reach maximum stress during simple traction and compression tests.

were derived from the time taken to reach the maximum stress during loading (for these tests constant force rates were applied up to the maximum stress, on cylindrical samples with a diameter equal to $10 \mathrm{~mm}$ and a length of $20 \mathrm{~mm}$, and temperature ranging between -60 and $+120^{\circ} \mathrm{C}$ ). The plot obtained from these earlier tests is monotonic, while the equivalence obtained here by DMA, with test conditions \#1, shows a less regular behaviour with several points of inflexion. However, applying the old equivalence relationship to our measurements does not bring together plots for reduced times greater than $1 \mathrm{~s}$ sufficiently (especially for logarithms of reduced time greater than 9 ). In the case of lower values of the reduced times, it is the equivalence obtained by DMA that could probably be corrected, given the difficulty of 'realigning' the plots when they are flat.

The master curve of the imaginary modulus (Fig. 1) is obtained by direct application of the equivalence derived from the real modulus. Processing the data in this way gives a 'reasonable' curve for the imaginary modulus. Under these operating conditions, the real modulus at $-100^{\circ} \mathrm{C}$ was close to $8.5 \mathrm{GPa}$. This modulus had fallen by only $1 \mathrm{GPa}$ at $-60^{\circ} \mathrm{C}$. However, the modulus fell sharply between -60 and $-10^{\circ} \mathrm{C}$. The glass transition temperature in this area was determined to be $-40^{\circ} \mathrm{C}$ using a specific series of tests with more closely spaced temperature steps. A secondary transition occurred in the real modulus at around $+30^{\circ} \mathrm{C}$. Finally, the real modulus at $+100^{\circ} \mathrm{C}$ was $3 \mathrm{GPa}$.

\section{Irreversibility of the behaviour}

\subsection{Experimental observations and influence of the operating mode}

Measurements have shown a disparity in the real Young's modulus as a function of the operating conditions (Fig. 3). While the initial real modulus at $20^{\circ} \mathrm{C}$ is always close to $6 \mathrm{GPa}$ (Table 1 , cond. $\# 1, \mathrm{~A}$ ), it falls to $5.39 \mathrm{GPa}$ if an excursion to $5^{\circ} \mathrm{C}$ is imposed before starting the experiment (Table 1 , cond. \#1, C), and to $3.9 \mathrm{GPa}$ following an excursion to $-100^{\circ} \mathrm{C}$ (Table 1 , cond. \#1, $\mathrm{D} \rightarrow \mathrm{E}$ meaning value obtained at $20^{\circ} \mathrm{C}$ between phases $\mathrm{D}$ and $\mathrm{E}$ ). Coming back to the ambient temperature of $20^{\circ} \mathrm{C}$, the final modulus was equal to 4.5 GPa. We observed that these conclusions were independent of the frequency. The loss angle tangent at $20^{\circ} \mathrm{C}$ did not change during the test. An identical phenomenon has also been observed with PBX 9501 [1]. We therefore propose a number of additional tests (Table 1, cond. \#2 to \#5) and a discussion on the possible causes of this phenomenon. 


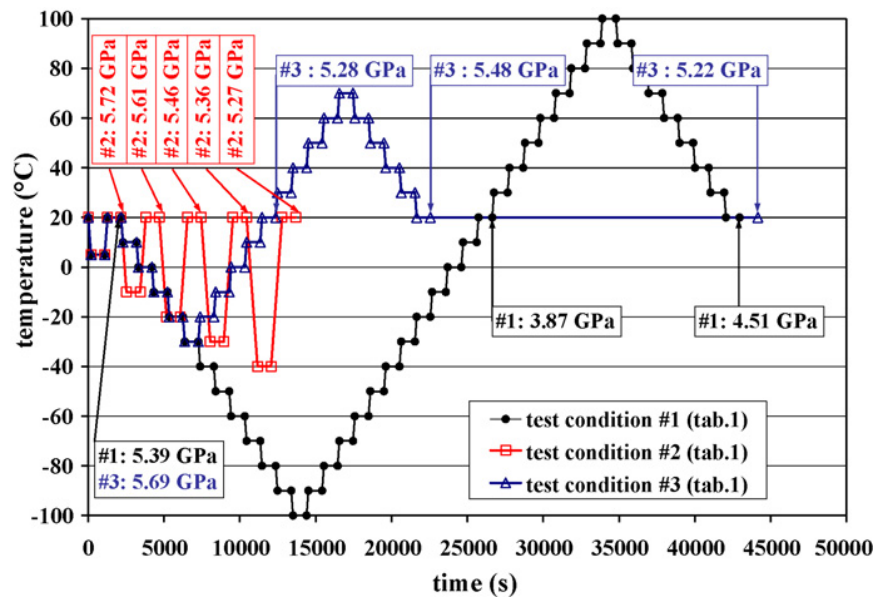

Fig. 3. Heating and cooling protocols for test cond. \#1 (black), \#2 (red) and \#3 (blue). The real modulus measured at $+20^{\circ} \mathrm{C}$ is indicated for cond. \#1 to \#3. (For interpretation of the references to color in this figure legend, the reader is referred to the web version of the article.)

Several explanations could be related to the operating mode used. If the thermal equilibrium was suspect, one would expect to see a higher value than the initial modulus during the heating phase (cond. \#1, D $\rightarrow E$ ). However, the inverse is observed. In addition, doubling the time allowed to reach equilibrium at each step and using a high frequency sensor (less sensitive to temperature variations) has not eliminated the 'anomaly'.

In order to eliminate the adhesive as a possible cause, a test was carried out over a restricted temperature range of between 20 and $-40{ }^{\circ} \mathrm{C}$ (Table 1 , cond. \#2). A new step at $20^{\circ} \mathrm{C}$ was inserted between each step at a lower temperature. These measurements showed that the modulus decreases continually with the low temperature reached. The phenomenon cannot therefore be explained by any degradation of the adhesive. These additional measurements show that the operating mode used is not the source of the anomaly. There must be actual 'damage' or 'healing' of the material as a function of the temperatures reached.

\subsection{Healing at high temperature}

We have measured the behaviour of a sample at $20^{\circ} \mathrm{C}, 6 \mathrm{~h}$ after a test involving a temperature excursion to $-30^{\circ} \mathrm{C}$ followed by one to $+70^{\circ} \mathrm{C}$ (Table 1 , cond. \#3). The final value obtained was close to that measured during the heating phase (Table 2). We conclude that some form of 'damage' occurs when the material is exposed to low temperatures. The origin of this damage is still to

Table 1

Thermal loading applied. Figs. 1 and 2 were obtained using operating cond. \#1.

\begin{tabular}{|c|c|c|c|c|c|}
\hline & \multicolumn{5}{|c|}{ Conditions } \\
\hline & $\# 1$ & \#2 & \#3 & $\# 4$ & $\# 5$ \\
\hline Thermal rate $\left({ }^{\circ} \mathrm{C} / \mathrm{min}\right)$ & 5 & 5 & 5 & 0.2 & 0.2 \\
\hline Time to equilibrium (min) & 15 & 15 & 15 & 5 & 5 \\
\hline \multicolumn{6}{|l|}{ Imposed temperatures $\left({ }^{\circ} \mathrm{C}\right)$} \\
\hline A & +20 & +20 & +20 & +20 & +20 \\
\hline B & +5 & +5 & +5 & -90 & -90 \\
\hline $\mathrm{C}$ & +20 & +20 & +20 & +20 & +70 \\
\hline $\mathrm{D}$ & -100 & -10 & -30 & & +20 \\
\hline $\mathrm{E}$ & +100 & +20 & +70 & & \\
\hline $\mathrm{F}$ & +20 & -20 & +20 & & \\
\hline G & & +20 & & & \\
\hline $\mathrm{H}$ & & -30 & & & \\
\hline I & & +20 & & & \\
\hline $\mathrm{J}$ & & -40 & & & \\
\hline $\mathrm{K}$ & & +20 & & & \\
\hline
\end{tabular}

Table 2

Real modulus (in GPa) at $1 \mathrm{~Hz}$, measured for different operating conditions (Table 1).

\begin{tabular}{|c|c|c|c|c|}
\hline & \multicolumn{4}{|c|}{ Conditions } \\
\hline & $\# 1$ & \#3 & $\# 4$ & \#5 \\
\hline Initial (C) & 5.39 & 5.69 & 5.68 & 5.49 \\
\hline Heating phase $(D \rightarrow E)$ & 3.87 & 5.28 & & 4.54 \\
\hline Final $(F)$ & 4.51 & 5.48 & 4.66 & 4.81 \\
\hline After $6 \mathrm{~h}$ at $20^{\circ} \mathrm{C}$ & & 5.22 & & \\
\hline
\end{tabular}

be determined. The partial 'healing' phenomenon observed following exposure to high temperatures can only be due to a mechanism still to be identified with a characteristic time period of greater than $1 \mathrm{~h}$ (the time needed to return to $20^{\circ} \mathrm{C}$ during the nominal test). Beyond this time, the measured behaviour during the heating phase is identical to that obtained following a heating and cooling cycle, provided that the delay before measurement is sufficiently long.

\subsection{Measurements at low rates of change of temperature}

A number of additional tests were carried out using the same experimental set-up, but with slower rates of cooling and heating (Fig. 4), in order to provide data about the influence of the thermal rate. The first test (cond. \#4 in Table 1) began at $20^{\circ} \mathrm{C}$, and was then cooled to $-90^{\circ} \mathrm{C}$ (the equipment did not reach $-100^{\circ} \mathrm{C}$ as initially planned) at a mean cooling rate of $0.2^{\circ} \mathrm{C} / \mathrm{min}$. The temperature was then brought back to $20^{\circ} \mathrm{C}$ at the same rate. A $5 \mathrm{~min}$ stabilisation time was allowed at -90 and $+20^{\circ} \mathrm{C}$ steps (no measurements between these extreme temperatures). Measurements were taken at 1 and $10 \mathrm{~Hz}$ with a dynamic displacement of $\pm 3 \mu \mathrm{m}$.

The second test (cond. \#5 in Table 1) used a frequency sweep of $1-50 \mathrm{~Hz}$ (with a dynamic displacement of $3 \mu \mathrm{m}$ ) at $10^{\circ} \mathrm{C}$ steps between +20 and $-100^{\circ} \mathrm{C}$, then between -100 and $+70^{\circ} \mathrm{C}$, and finally between +70 and $+20^{\circ} \mathrm{C}$ ( 5 min stabilisation time).

The results for $1 \mathrm{~Hz}$ are given in Table 2 . The first point to note is the good reproducibility of the results of these tests at the first $20^{\circ} \mathrm{C}$ data compared with those from the earlier test. However, cooling at a slower rate resulted in higher values of the modulus. A value of $11 \mathrm{GPa}$ was observed at $-60^{\circ} \mathrm{C}$ compared with a value of around $7.5 \mathrm{GPa}$ for the tests carried out at a rate of $5{ }^{\circ} \mathrm{C} / \mathrm{min}$. Reducing the temperature further resulted in a fall in the value of the real modulus to reach a point very close to the value recorded at $-90{ }^{\circ} \mathrm{C}$ during the $5^{\circ} \mathrm{C} / \mathrm{min}$ tests (compare for example Figs. 1 and 6

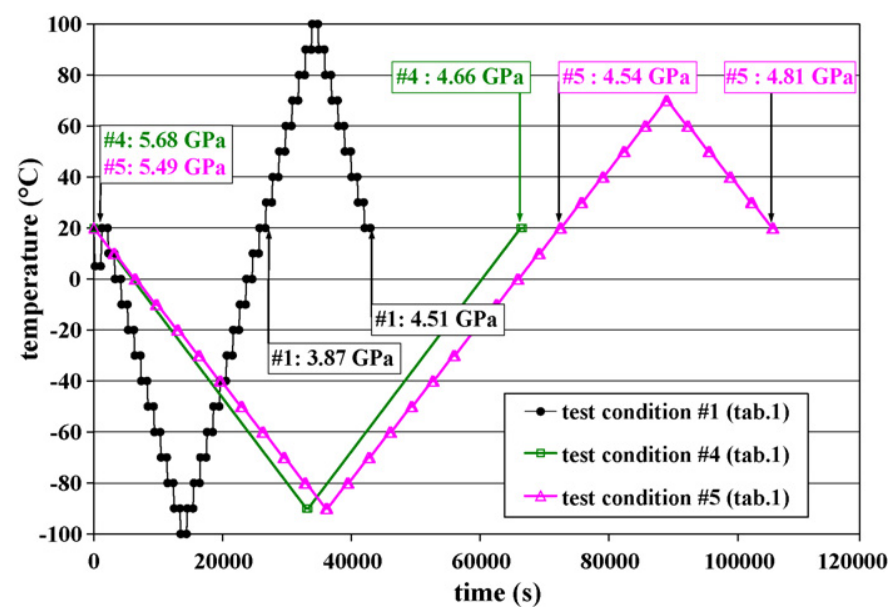

Fig. 4. Heating and cooling protocols for test cond. \#4 (green) and \#5 (pink). Test cond. \#1 is remembered (black). The real modulus measured at $+20^{\circ} \mathrm{C}$ is indicated for cond. \#1, \#4 and \#5. (For interpretation of the references to color in this figure legend, the reader is referred to the web version of the article.) 


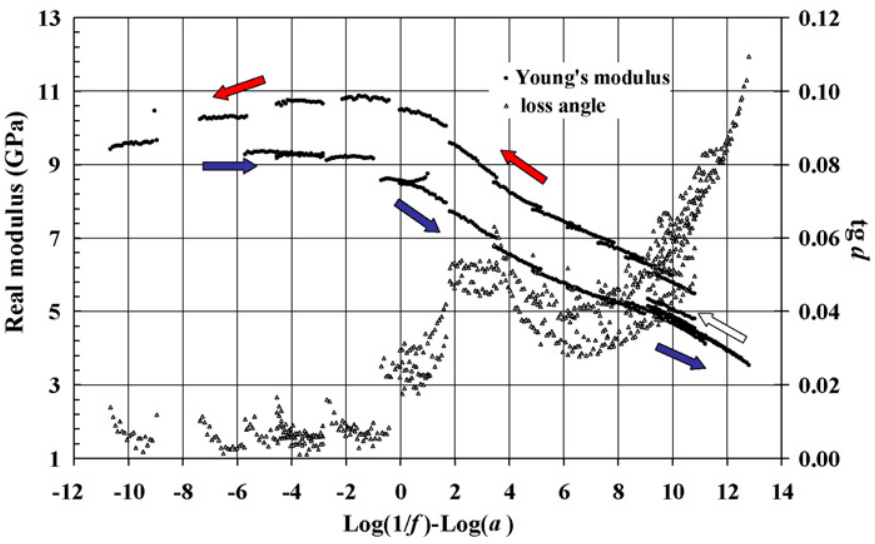

Fig. 5. Changes to the real modulus as a function of time and temperature $\left(0.2^{\circ} \mathrm{C} / \mathrm{min}\right.$, dynamic displacement of $\pm 3 \mu \mathrm{m}$, frequencies between $1 \mathrm{and} 50 \mathrm{~Hz}$ ) Time-temperature equivalence relationships derived from DMA tests at $0.2{ }^{\circ} \mathrm{C} / \mathrm{min}$. For the Young's modulus, the first cooling conditions (from +20 to $-90^{\circ} \mathrm{C}$ ) are indicated using red arrows. Then, blue arrows indicate the response of the material during the heating process (from -90 to $+70^{\circ} \mathrm{C}$ ). Returning to +20 from $+70^{\circ} \mathrm{C}$ gives a third branch of the master curve parallel to the white arrow. For the loss angle, cooling and heating protocols lead to the same master curve. (For interpretation of the references to color in this figure legend, the reader is referred to the web version of the article.)

for reduced time equal to -8 ). We have no explanation for this new temperature effect on the behaviour (seen also in PBX 9501 [1]).

In spite of the decrease mentioned previously, the modulus eventually reached at $-90^{\circ} \mathrm{C}$ remained considerably higher (around $10 \mathrm{GPa}$ ) when the rate of temperature change was lower. These tests also showed the same phenomenon that occurred during the tests with a higher rate of change of temperature, a value of the real modulus at $+20^{\circ} \mathrm{C}$ that was $25 \%$ lower relative to the initial modulus. Slowing the rate of change of temperature also appeared to decrease (but not suppress) the loss of the real modulus. It could be assumed that thermal loading conditions act as mechanical loading and involve the viscous behaviour of the material. But the original modulus is not entirely recovered, showing the existence of an irreversible mechanism. It may be noted that the imaginary modulus is not affected by thermal cycling.

The results from the operating conditions \#5 were processed in order to determine the time-temperature equivalence. It can be seen that the equivalence derived in the past during simple compression tests gives a better result for the real Young's modulus. However, this equivalence has been corrected for long time periods in order to obtain a more closely aligned master curve (Fig. 5). A comparison of the equivalences is given in Fig. 2. However, it should be noted that the equivalence obtained during the $0.2^{\circ} \mathrm{C} / \mathrm{min}$ tests does not work for the imaginary modulus below $-50^{\circ} \mathrm{C}$ (Fig. 5) regardless of the offset factors plot used.

\subsection{Measurements on the binder}

Using lowest as possible thermal rates, we have made an experimental study on two other materials. The first one is a mock material made of inert crystals and approximately the same binder. This material was previously densified using our isostatic high pressure facility and similar process than the explosive composition. Running test cond. \#4 led to a variation of the sample stiffness of less than $1.5 \%$ when it was returned to $20^{\circ} \mathrm{C}$.

In spite of (1) the small amount of binder into the explosive composition and, as a consequence, its presence as thin layers of thickness around few hundreds angstrom and (2) the high loading conditions applied during the isostatic compaction process of the composition, some measurements have been made on millimetricsized samples of pure binder allowing, at least, comparing the initial and final stifnesses at $20^{\circ} \mathrm{C}$. After applying $-100^{\circ} \mathrm{C}$ thermal condi- tion with a higher dynamic strain (dynamic displacement $\pm 30 \mu \mathrm{m}$ to 'model' possible local amplified displacements due to heterogeneity), a maximum evolution of $5 \%$ of the binder stiffness was recorded.

\subsection{Discussion about 'damage' at low temperatures}

Let us summarize the observed phenomena: (1) a decrease of the Young's modulus is observed after a thermal cycle involving low temperature when the same imaginary modulus is obtained; (2) this decrease is attenuated (but not suppressed) if thermal rate is decreased; (3) this decrease is observed even for a small decrease of the temperature far below the glass transition temperature; (4) this decrease is unchanged even after several hours at rest; (5) experiments made on the pure binder and an inert simulant have not exhibited significant irreversibility of their own behaviours.

Due to small strain applied during tests, it is likely that the origin of this phenomenon lies in microstructural deformation mechanisms coming into play during the test. The material consists of large grains held within a matrix of smaller grains, a polymer binder, and porosity [11]. Micrographs show the presence of many micro cracks and localised porosity within the matrix (Fig. 6). In order for the real modulus to be affected, at least one of the following conditions must be satisfied: (I) the intrinsic behaviour of one of the constituents (grains or binder) changes, (II) the porosity increases, (III) the number of micro cracks increases, (IV) the physical and chemical interaction forces at the interface between the binder and the grains evolve (the adhesion of the binder to the HMX decreases), (V) the coefficient of friction between grains, or between the two sides of an intra granular crack, changes, (VI) the internal stresses, locked into the material during the forming process and not totally released, increase at low temperature and (VII) the material is sensitive to humidity, or to the nitrogen used during the tests.

In the first part of the discussion, the following possible causes are eliminated:

- The absorption of water results in a reduction of rigidity due to the destruction of mechanical cohesion within the macromolecular mesh. It should be noted that reducing the rate of change of temperature should favour the phenomenon of hygroscopy by increasing the time available for molecule to migrate through the composite. However, we observed an increase in the modulus at a lower rate of change of temperature. We can therefore exclude hygroscopy and any permeability-based mechanism as a possible cause of the observed irreversibility.

- Any changes to the crystalline behaviour (and hence the coefficient of friction between grains) may immediately be excluded as the low temperatures are far from those of any phase change (the $\beta-\delta$ transition of HMX occurs at around $180^{\circ} \mathrm{C}$ ). Futhermore, the phenomenon has also been observed for small temperature changes close to ambient.

- The material is formed by isostatic compaction. The pressures applied are very much greater than those occurring during the DMA tests (100 MPa against $0.2 \mathrm{MPa}$ ). Moreover, microstructural observations have shown that the application of a uniaxial stress (quasi-static or dynamic) does not result in any plastic deformation of the grains [11].

The composition of such materials and existing data point the important role of the binder into the behaviour of these composite materials. Unfortunately, the lower variation on the recovered Young's modulus recorded using a simulant (containing a significant higher mass fraction of binder) shows that the cause of irreversibility is not the binder alone. This conclusion is confirmed with observations made using pure binder samples. Thus, the first 

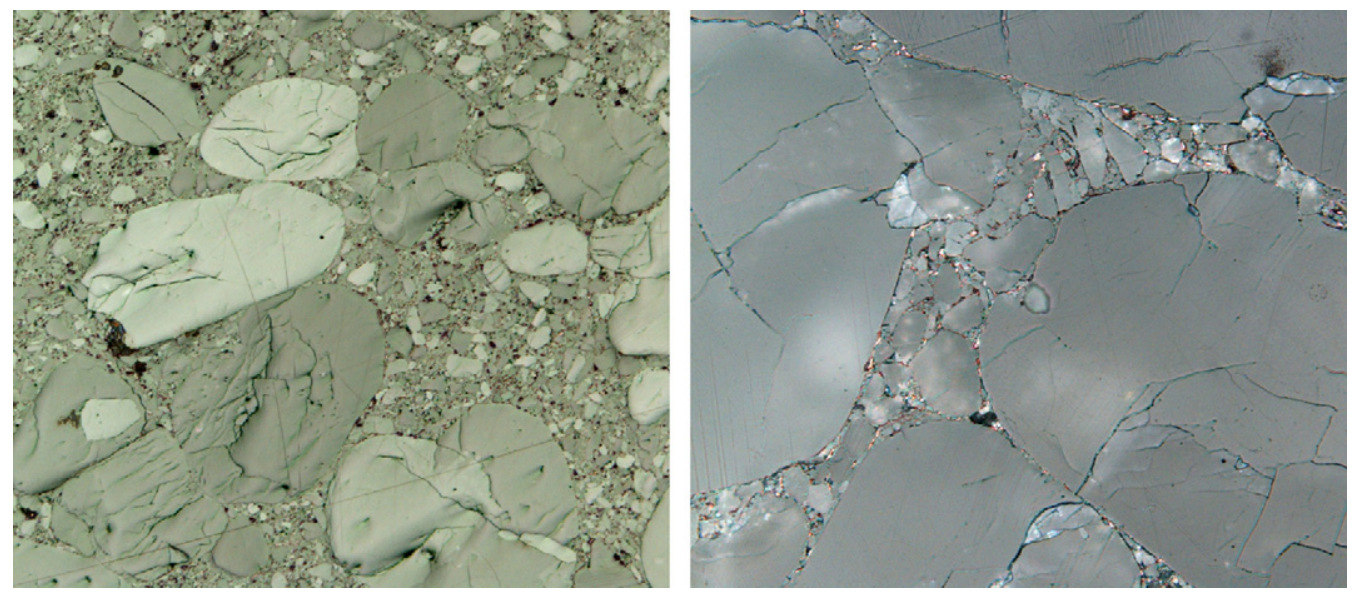

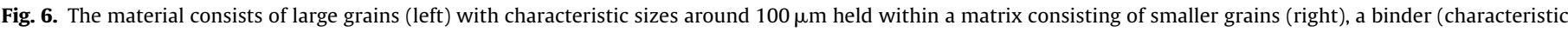
local dimension is less than the resolution of the optical method), and areas of porosity [11]. These photographs have been obtained on "damaged" samples.

idea is that the key phenomenon is located in the grain/binder interaction. We do not have experimental information to pass judgement on the role and evolution of the binder/grain physicochemical behaviour for stress-free loading conditions. The adhesive law needs to be investigated. On the other side, the grain/binder interface is probably submitted to a tensile load as the temperature decreases, due to a higher cubic coefficient of thermal expansion for the polymer than for HMX. Classically, this coefficient is at least three times higher for polymers (approx. $500 \times 10^{-6} / \mathrm{K}$ ) than for HMX (approx. $150 \times 10^{-6} / \mathrm{K}$ ). Therefore, as the explosive is cooled, the binder contracts more than the filler creating local stresses.

One could expect a relaxation of this stresses with time due to the viscoelastic behaviour of the binder. This is partially true but lower thermal rate and experiments with long duration rest conditions have not permitted to recover the whole stiffness of the material. Observing that the imaginary modulus is not affected, the temperature reached rather than the rate of change of temperature determines the degradation of the material (as observed also during test cond. \#2, Fig. 3). Thus, the second idea is that the viscoelastic behaviour of the binder cannot alone explain such irreversibility.

Any increase of intra granular micro cracks, due to the local tension generated by different dilatational coefficients, requires the assumption that the large grains are 'embedded' at their edges and subjected to tensile conditions. This mechanism does not seem likely, given that the binder is more flexible than the HMX crystals. On the other side, given the evolution of the heterogeneity of the local stresses, the contact forces may redistribute during cooling, encouraging the reorganisation of the chains of forces between the grains. This phenomenon has been clearly identified in dry sands subjected to alternating stresses or thermal cycling. However, it would require a change of approximately $20 \%$ of the porosity to result in a $40 \%$ fall in the value of Young's modulus. Microstructural observations made on recovered samples did not show such an evolution.

It could be assumed that the cooling process results in tensions in the binder filaments and binder/grain interfaces due to the thermal contraction of the constituents. If some of the bonds between the constituents fail, the material will become more flexible as the number of micro cracks increases. These micro cracks should be localised between the largest grains and the matrix (binder and smallest particles) where the relative displacement is highest. However, microstructural examinations carried out as part of this study have revealed no significant changes in this parameter.

This discussion and provided experimental data show that irreversibility probably comes from a degradation of the binder itself (if adhesion behaviour is assumed unchanged), when used as part of a composite material. Experiments made using two fillers show a dependence on (1) the nature of the filler (meaning different dilatational coefficient or adhesion properties between binder and grains) or on (2) the volume fraction of filler (number of loaded interfaces). We can assume that local tensile conditions lead to strain and break crosslinks into the binder rather than micro cracks growth.

\section{Conclusion}

The mechanical behaviour of explosive materials has been studied for a number of years with the aim of improving understanding of these materials and developing increasingly effective models for use in pyrotechnic design and safety applications. Significant progress has been made in recent years, particularly in the development of quasi-static models and experimental methods for the study of dynamic stresses. This study forms part of that programme, focusing on measurements made using a viscoanalyser (mechanical spectrometry).

The originality of this paper is an attempt to understand the causes of the important decrease of the stiffness observed during thermal cycles. A 'damage' phenomenon develops as a result of temperature changes and we have shown that this phenomenon may be associated with a degradation of the binder macromolecules or with an evolution of the adhesion properties at the binder/grains interfaces (not evaluated in this paper). This conclusion is based on various thermal loading conditions, microstructural observations of initial and 'damage' samples (no significant evolution of the micro crack pattern) and on DMA measurements made using a mock material or the binder.

The development of an operating mode suitable for this material has made it possible to identify a time-temperature equivalence relationship allowing all the measurements to be included on a single master curve using an equivalence factor defined as a function of the temperature. While earlier techniques required several hundred tests in order to determine this equivalence relationship, using the DMA method required less than five tests to obtain this information.

Future works are now devoted to the relation between DMA data and high strain rate measurements, as the one obtained using Split Hopkinson Pressure Bars. An increase of the maximum stress is shown for some material as the strain rate exceeds $10-100 \mathrm{~s}^{-1}$. This increase is attributed to several mechanisms as (i) inertial effects during compression and (ii) for brittle-like material as glass and ceramics, a change in the failure mechanism [12] (a macrocrack develops at lower strain rate, a multi fragmentation mechanism 
could be assumed for higher rate levels). Williamson [1,2] has shown that such increase could also be explained using quasi-static measurements and a time-temperature equivalence for the explosive composition PBX 9501.

\section{Acknowledgements}

Authors would like to thank H. Trumel (CEA) and P. Lambert (Sciences \& Applications) for providing Fig. 6.

\section{References}

[1] D.M. Hoffman, J. Appl. Polym. Sci. 83 (2002) 1009-1024.

[2] D.M. Williamson, C.R. Siviour, W.G. Proud, S.J.P. Palmer, R. Govier, K. Ellis, P. Blackwell, C. Leppard, J. Phys. D: Appl. Phys. 41 (2008) 085404.

[3] C.M. Cady, W.R. Blumenthal, G.T. Gray III, D.J. Idar, Polym. Eng. Sci. (2006)
[4] E.M. Mas, B.E. Clements, et al., in: M.D. Furnish, N.N. Thadhani, Y. Horie (Eds.), Shock Compression of Condensed Matter, 2001.

[5] M. Gratton, V.-D. Le, A. Frachon, M. Caliez, D. Picart, WSEAS Trans. Comput. 5 (1) (2006) 149-156.

[6] A. Frachon, M. Caliez, M. Gratton, V.-D. Le, D. Picart, Proc: 7th World Congress on Computational Mechanics (WCCM VII), California, USA, 2006

[7] V-D. Le, M. Caliez, M. Gratton, A. Frachon, D. Picart, Proc: 3rd Int Conf. HPSM: High Performance Struct. Mater. III, vol. 3, no. 1, Ostende, Belgium, 2006, pp. $211-223$.

[8] M. Gratton, V.-D. Le, M. Caliez, A. Frachon, D. Picart, Proc: WSEAS/IAME Int. Conf. System Sci. Simulation Eng., Tenerife, Spain, 2005, pp. 106113.

[9] C. Gruau, D. Picart, Foundation Civil Environmental Eng., Editor Publishing House of Poznan University of Technology, 2008.

[10] METRAVIB RDS User's Guide, Metravib RDS 200 chemins des Ormeaux, 69760 Limonest, France.

[11] H. Trumel, P. Lambert, R. Belmas, Proc: Int. Detonation Symposium, Coeur d'Alene, USA, 2010

[12] C. Denoual, F. Hild, Comp. Meth. Appl. Mech. Eng. 183 (2000) 247-258. 